\title{
Uma Avaliação da Teoria da Doença Holandesa e da Hipótese da Maldição dos Recursos Naturais*
}

\section{An Evaluation of the Dutch Disease Theory and the Resource Curse Hypothesis}

Clarissa Black**

Resumo: Este artigo propõe uma discussão sobre a teoria da doença holandesa, seus antecedentes e as suas principais críticas. Apresenta-se o modelo estático, que demonstra os mecanismos de transmissão da doença holandesa para a economia. Expõe-se também o modelo dinâmico, baseado na teoria do crescimento endógeno e com princípios de doença holandesa, utilizado como explicação para a maldição dos recursos naturais. Por fim, evidenciam-se as principais críticas teóricas e metodológicas desses modelos.

Palavras-chave: Doença holandesa. Maldição dos recursos naturais. Desenvolvimento econômico.

\begin{abstract}
In this article, we propose a discussion of the theory of Dutch disease, its history and its main criticism. We show the static model that demonstrates the transmission mechanisms of the Dutch disease for the economy. We also expose the dynamic model based on the endogenous growth theory and principles of the Dutch disease, regarded as an explanation for the resource curse hypothesis. We present the main theoretical and methodological criticism of these models.
\end{abstract}

Keywords: Dutch disease. Resource curse. Economic development.

JEL Classification: O13; Q32; Q33.

Artigo apresentado na Segunda Reunião Ibero-Americana de Socioeconomia, ocorrida em Porto Alegre, Rio Grande do Sul, em novembro de 2015.

** Doutoranda em Economia pelo Programa de Pós-Graduação em Economia (PPGE) da Universidade Federal do Rio Grande do Sul (UFRGS). Pesquisadora e Economista da Fundação de Economia e Estatística (FEE). E-mail: clarissa@fee.tche.br 


\section{1 lntrodução}

Diversos autores ao longo da história do pensamento econômico têm demonstrado preocupações em relação ao desenvolvimento econômico em regiões férteis ou com abundância de recursos naturais. Para os clássicos, em especial Mill (1996), ${ }^{1}$ os trabalhadores de regiões férteis teriam uma tendência maior à indolência. Já para Cairnes ( $1873^{2}$ apud BOIANOVSKY, 2012), um boom no setor de minérios causaria descultivo e desindustrialização, em uma análise com princípios do que um século depois seria denominada doença holandesa, conforme o modelo de Corden e Neary (1982).

Stijns (2005) ressalta que a verificação de que os países pobres em recursos tenderiam a um desempenho econômico superior aos países ricos em recursos é recorrente na história econômica. Comparações entre Holanda e Espanha no século XVIII e Suíça e Japão contra Rússia nos séculos XIX e XX ilustram o debate ao longo da história.

Sachs e Warner (1995) observam o desempenho econômico inferior dos países ricos em recursos naturais em vários períodos ao longo da histórica econômica, em especial a performance superior de países pobres em recursos naturais do Leste Asiático, como Coreia, Taiwan, Hong Kong e Singapura, em comparação com países com abundância de recursos, como México, Nigéria e Venezuela após os anos 60 do século passado.

Diante disso, os autores separam a literatura que busca explicações para a hipotética relação inversa entre crescimento econômico e abundância de recursos naturais em: a) argumentos de caráter político e econômico; b) comportamento rent-seeking, que ocorre na disputa pelas rendas originadas da exploração dos recursos naturais; c) doença holandesa; d) hipótese de Prebisch e Singer; e) potencial reduzido de encadeamentos para frente e para trás no setor de recursos naturais comparado com o setor manufatureiro; e f) diminuição do processo de learn-by-doing.

Por sua vez, para Lederman e Maloney (2008), a literatura coloca as seguintes motivações para a maldição dos recursos naturais: a) tendência ao declínio dos preços reais de commodities; b) menor acúmulo de capital físico e humano e produtividade e externalidades inferiores; c) doença holandesa; e d) enfraquecimento das instituições.

Por outro lado, a utilização de medidas alternativas para calcular a abundância dos recursos naturais, especialmente a ponderação das exportações de commodities pelo número de trabalhadores, proporcionou um divisor de águas no debate: a abundância de recursos naturais passou a ter uma relação positiva com

$1 \quad$ A data da publicação original é 1848.

2 CAIRNES, J. E. Essays in political economy. London: Macmillan, 1873. 
o crescimento econômico (LEDERMAN; MALONEY, 2007). Os casos de sucesso, como o do Canadá, da Nova Zelândia e da Noruega, confirmam essa proposição de que os recursos naturais não são um fardo à economia (SINNOTT; NASH; TOR$\mathrm{RE}, 2010)$ e que o que de fato importa é a política interna, ou seja, a forma como esses recursos são geridos e investidos (FISHLOW; BACHA, 2010). As relações externas também não podem ser negligenciadas, especialmente questões de ordem geopolítica (MEDEIROS, 2013).

Frente a esse contexto, o objetivo deste estudo é fazer uma avaliação crítica da teoria da doença holandesa e da hipótese da maldição dos recursos naturais. Para atender a esse objetivo, a segunda seção apresenta os antecedentes das ideias que fundamentam o fenômeno da doença holandesa, com base na história do pensamento econômico; a terceira seção aborda o modelo estático de doença holandesa com base em Corden e Neary (1982); a quarta seção expõe sua versão dinâmica, que embasou a hipótese da maldição dos recursos naturais de Sachs e Warner (1995), os quais consideram a doença holandesa a principal explicação para a maldição dos recursos naturais; a quinta seção aborda as principais críticas ao modelo dinâmico de doença holandesa e à tese da maldição dos recursos naturais, assim como ao modelo estático de doença holandesa; e, por fim, na sexta seção são tecidas algumas considerações finais.

Diante disso, a principal contribuição deste artigo é a compilação dos principais aspectos teóricos que envolvem o tema da doença holandesa e da maldição dos recursos naturais e a apresentação das suas principais críticas teóricas e metodológicas. A importância deste estudo remete à necessidade de não negligenciar essas incoerências teóricas nas aplicações empíricas em torno do tema.

\section{Antecedentes das Ideias da Doença Holandesa}

Conforme Davis (1995), a doença holandesa corresponde a uma situação de simultaneidade de setores em crescimento e setores em retrocesso, em meio a uma elevação, temporária ou permanente, das rendas com exportação de recursos naturais, tanto por meio da valorização dos preços internacionais, quanto através de novas descobertas.

O conceito atual de doença holandesa, segundo Priewe (2012), em um estudo para a United Nations Conference on Trade and Development (UNCTAD),

[...] refere-se a uma situação na qual a descoberta de novos recursos naturais de um país ou um boom nos preços de tais recursos conduz a uma apreciação real da moeda do país, o que, por sua vez, pode dificultar o crescimento do setor manufatureiro ou de outros bens comercializáveis (PRIEWE, 2012, p. 1, tradução nossa). 
O termo foi cunhado pela revista The Economist, na sua edição de 26 de novembro de 1977, em referência à apreciação cambial na Holanda, com origem no boom das exportações de gás natural e nas preocupações quanto aos seus efeitos adversos sobre o setor manufatureiro. Apesar do termo "doença holandesa" ter surgido apenas na segunda metade do século XX, a discussão sobre o seu conceito surgiu muito antes na história do pensamento econômico (SINNOTT; NASH; TORRE, 2010).

Na origem das ideias dessa teoria, está o trabalho de Cairnes, que estudou os efeitos negativos de um boom no setor mineral para a indústria e a agricultura através da desindustrialização e da redução na produção agrícola (CAIRNES, $1873^{3}$ apud BOIANOVSKY, 2012). A disponibilidade de rendas oriundas da exploração de recursos naturais tornava mais atrativa a aquisição dos bens necessários no comércio internacional, ao invés de produzi-los domesticamente (CAIRNES, 1873³ apud SINNOTT; NASH; TORRE, 2010).

Ao analisar os efeitos para a economia australiana da descoberta de ouro do século XIX, o autor verificou que uma primeira consequência desse boom de recursos teria sido o aumento dos salários monetários, o que teria tornado menos competitiva a produção agrícola e manufatureira na Austrália. Isso pode ser considerado um movimento de valorização da taxa real de câmbio, na medida em que o trabalho é um fator de produção não tradable.

Cairnes (1873³ apud BOIANOVSKY, 2012), ao supor pleno emprego de fatores e a teoria das vantagens comparativas, afirmava que um aumento na lucratividade do setor exportador de recursos, seja frente a novas descobertas, seja em função de uma valorização nos preços internacionais desses produtos, criava desvantagens para a produção nos demais setores da economia.

Apesar de a literatura mais recente sobre doença holandesa dar maior ênfase ao problema da desindustrialização, inicialmente se considerava que haveria efeitos danosos à rentabilidade tanto industrial, quanto agrícola frente a um boom de minérios, com consequente redução da produção primária e desindustrialização (CAIRNES, 1873 apud BOIANOVSKY, 2012).

Seers (1964) descreve a paradoxal situação de algumas economias exportadoras de petróleo na forma de uma coexistência de desemprego, desindustrialização e altos salários, com base em seu estudo sobre a economia venezuelana. O autor destaca que esse aumento do desemprego em estados rentistas é consequência dos salários elevados e de políticas inapropriadas para o desenvolvimento da indústria local.

Para o autor, a taxa de crescimento do emprego em economias dependentes das exportações de petróleo seria em função do diferencial entre o crescimento das exportações - não importa se em volume ou em preço - e o crescimento dos

3 CAIRNES, J. E. Essays in political economy. London: Macmillan, 1873. 
salários. O autor explica que, como os gastos do governo são financiados principalmente pelas receitas do petróleo, e que uma parte importante dessas despesas é destinada ao pagamento de salários, quanto maior for o salário, menor será a quantidade de emprego na economia.

Outros fatores que atuariam no sentido de reduzir o emprego na economia seriam: as reduzidas taxas sobre exportações, a elevada propensão a importar, o aumento das margens de lucro e o superávit fiscal do governo. Seers (1964, p. 236, tradução nossa) relata o paradoxo de altos salários e desemprego em economias produtoras de petróleo, caracterizadas por tensões não aparentes no seu balanço de pagamentos:

A maioria das economias não petrolíferas têm sentido cada vez mais as tensões causadas por um crescimento lento das exportações e aumento rápido das importações: elas têm tomado muitas medidas de proteção e, até mesmo, de geração de emprego, mas que são destinadas, na verdade, em primeiro lugar, para proteger as reservas. As economias petrolíferas operam diferentemente. Fatores que em outros lugares se expressariam em crise de balanço de pagamento, tais como aumentos salariais ou iniciativas inadequadas no desenvolvimento da indústria local, aqui irão causar desemprego.

Ademais, os gastos do governo em economias rentistas não impactam os setores produtivos da economia, de modo que as rendas externas são utilizadas para importar bens de consumo, o que teria relação com a moeda sobrevalorizada dos estados rentistas. Nas palavras de Madhavy (1970, p. 436, tradução nossa):

[...] a matriz insumo-produto das economias rentistas tem que mudar tão drasticamente que a demanda interindústria da matriz não permaneça "subdesenvolvida", quando comparada com a parte da demanda. Porque, se a maior parte da renda externa é usada para importar para fins de consumo, todos os setores produtivos da economia permanecerão relativamente intocados por esses gastos "extraordinários".

Após a apresentação dessas ideias que convergem para o conceito de doença holandesa e o precederam, nas próximas seções apresentam-se as versões estática e dinâmica dos modelos de doença holandesa. 


\section{Versão Estática do Modelo de Doença Holandesa}

Com base em pressupostos neoclássicos, Corden e Neary (1982) desenvolvem um modelo de doença holandesa estático com três setores - o de serviços, o produtor de petróleo e o manufatureiro - para analisar as consequências na redistribuição da renda e na rentabilidade do setor industrial de um boom no setor de energia, com as seguintes abstrações: a) não há consideração de questões monetárias, o modelo é baseado em uma economia de trocas simples; b) o progresso tecnológico é Hicks neutro; c) o produto nacional e os gastos são constantes; d) a balança comercial é equilibrada; e) salários são perfeitamente flexíveis; f) há pleno emprego de fatores em qualquer momento; g) há mobilidade intersetorial de fatores; h) a demanda por trabalho é função decrescente da razão entre salários e o preço do produto do setor.

Em seu core model, ao analisar o efeito de um aumento dos preços internacionais dos combustíveis em termos de emprego e produto, os autores separam os efeitos na economia em dois: deslocamento de fatores e despesa.

O efeito deslocamento de fatores ocorre quando o aumento de preços internacionais dos combustíveis causa uma elevação da rentabilidade do setor de energia, o que aumenta a demanda por trabalho nesse setor e eleva o nível de salários da economia, diminuindo a demanda por trabalho nos setores serviços e manufatureiro e deslocando a mão de obra desses setores para o setor de energia. Por esse motivo, o efeito deslocamento de fatores é denominado pelos autores de "desindustrialização direta", pois há redução na produção industrial em consequência da redução do emprego nesse setor (CORDEN; NEARY, 1982).

O efeito despesa, por sua vez, considera que uma renda mais elevada, devido ao aumento de preços dos combustíveis, aumentaria a demanda por serviços à taxa de câmbio real inicial. Dessa forma, para restaurar o equilíbrio, uma apreciação real da taxa de câmbio deveria ocorrer. Em outras palavras, o setor serviços seria contraído pelo primeiro efeito, mas expandido pelo segundo. Qual deles será o efeito dominante dependerá da magnitude de cada um deles na economia.

No entanto, no setor manufatureiro não ocorreria esse resultado ambíguo, pois os dois efeitos atuariam no mesmo sentido de diminuir o emprego e, consequentemente, a produção no setor industrial. No primeiro caso, a redução é direta, enquanto, no segundo, a diminuição é indireta, pois o aumento de demanda por trabalho no setor serviços, devido ao efeito despesa, aumentaria o nível de salários e reduziria o emprego e a produção industrial. Esse segundo efeito é chamado pelos autores de "desindustrialização indireta". Em suma, a indústria contrair-se-ia pela combinação entre redução na produção de serviços e de manufaturas (via efeito deslocamento de fatores) e aumento na demanda por serviços (via efeito despesa) (CORDEN; NEARY, 1982). 
Ademais, os autores ressaltam que o modelo de doença holandesa considera que o boom leva a uma apreciação real da taxa de câmbio, que é o aumento no preço dos bens não tradables em comparação com os tradables, enquanto outros autores tratam da valorização cambial como causa independente para a desindustrialização, quando, na verdade, a variação cambial é um efeito do processo de ajuste. Nas palavras de Corden e Neary (1982, p. 841, tradução nossa):

Além disso, mostrou-se neste modelo que o boom dá origem a uma apreciação real, ou seja, um aumento do preço relativo dos bens não transacionáveis em relação aos bens comercializados. (Esse resultado é, por vezes, apontado como uma causa independente de desindustrialização, no entanto, como mostra nossa análise, deveria mais propriamente ser visto como um sintoma do ajustamento da economia para o novo equilíbrio pós-boom).

Os autores admitem que, nos modelos em que consideram a possibilidade de mobilidade intersetorial de capital ${ }^{4}$ - ou seja, ao estender essa análise para o longo prazo - , não apenas a mobilidade de mão de obra, como supunha o seu core model, mas a desindustrialização pode não ser um resultado inevitável: “[...] em modelos posteriores, nos quais se permitiu a mobilidade intersetorial de mais de um fator, demonstrou-se que alguns desses resultados podem ser revertidos" (CORDEN; NEARY, 1982, p. 841, tradução nossa).

No caso do modelo com mobilidade de mais de um fator entre os três setores, os autores observam que "[...] somente quando a relação capital-trabalho no setor manufatureiro é intermediária entre a dos outros dois setores, a desindustrialização é um resultado assegurado" (CORDEN; NEARY, 1982, p. 839, tradução nossa).

Corden (1984) apresenta ainda uma versão sintetizada do chamado "modelo paradoxal", também presente em Corden e Neary (1982), no qual há mobilidade de capital somente entre os dois setores que não estão em boom, ressaltando que um deles é capital-intensivo, enquanto o outro é trabalho-intensivo. O produto do setor capital-intensivo pode se expandir como resultado do efeito deslocamento de trabalho para o setor em boom, ou seja, nessa situação um boom de recursos naturais poderia ter inclusive tendências industrializantes.

Diferentemente da versão neoclássica discutida até o momento, a versão estruturalista da doença holandesa não tem o pressuposto do pleno emprego e considera que a apreciação cambial com origem no boom de commodities é a principal causa para a desindustrialização em economias especializadas em recursos naturais. A maior propensão a importações e o desestímulo às exportações,

4 Para mais detalhes do modelo, ver Corden e Neary (1982), seção IV. 
seja em função dos custos salariais crescentes, seja em função do câmbio pouco competitivo, levaria as economias ricas em recursos naturais, entre elas o Brasil, à desindustrialização - perda da participação do emprego industrial e do valor adicionado da indústria, respectivamente no emprego total e no PIB - e a uma taxa de crescimento econômico inferior (BRESSER-PEREIRA, 2009).

\section{Versão Dinâmica da Doença Holandesa e Maldição dos Recursos Naturais}

Sachs e Warner (1995), através de uma análise cross-section, testam a relação entre abundância de recursos naturais e menor crescimento econômico. No modelo estimado pelos autores, é possível verificar uma relação inversa entre o crescimento econômico per capita entre 1970 e 1989 e o percentual das exportações de commodities (agricultura, minerais e agricultura) sobre o PIB para uma amostra de 97 países em desenvolvimento. Com base nesse resultado, concluem que "[...] uma das características surpreendentes da vida econômica moderna é que economias com poucos recursos frequentemente superam amplamente o crescimento econômico de economias ricas em recursos" (SACHS; WARNER, 1995, p. 2, tradução nossa).

Uma crítica comum para essa teoria é a existência de países ricos em recursos naturais que tiveram crescimento econômico robusto, tais como Malásia, Ilhas Maurício e Botswana, os quais parecem invalidar a hipótese de maldição dos recursos naturais. A resposta dos autores para esses outliers é o elevado grau de abertura econômica desses países e o fato de as manufaturas nesses países estarem conduzindo o crescimento econômico, e não um crescimento resource-led.

Sachs e Warner (1995) consideram que, atualmente, é muito menos decisivo para o desenvolvimento a disponibilidade de recursos naturais do que foi no passado, visto o barateamento dos custos de transportes. Ademais, consideram que "[...] a riqueza fácil leva à preguiça”"5 (SACHS; WARNER, 1995, p. 4, tradução nossa), ideia que converge para o pensamento de Mill (1996, p. 160), ao afirmar que "[...] o sucesso na produção, como a maior parte dos outros tipos de sucesso, depende mais das qualidades dos agentes humanos do que das circunstâncias em que operam; e o que alimenta a energia física e mental são as dificuldades, não as facilidades".

Os autores afirmam que a disponibilidade de recursos naturais é não somente não decisiva para o crescimento econômico, como também as evidências sinalizam para a existência de desvantagem para aqueles países que possuem recursos naturais, na forma de uma maldição que acomete os países com riqueza fácil e abundante.

5 Do original em inglês easy riches lead to sloth. 
Os autores desenvolvem um modelo dinâmico da doença holandesa com base da teoria do crescimento endógeno e como um modelo intergeracional com dois períodos: um no qual as pessoas trabalham e recebem salários e outro no qual se aposentam. No lado da demanda, o modelo assume que o governo redistribui os recursos com as vendas externas de recursos naturais para cada membro da população e os indivíduos devem escolher entre consumir hoje ou no futuro. Já no lado da oferta há três setores, como na versão estática do modelo: o setor de recursos naturais tradable, o setor de manufaturas tradable e um setor não tradable. Somente nos dois últimos setores há o emprego de capital e de trabalho. A fonte para o crescimento econômico nesse modelo é a mudança técnica que melhora a mão de obra, representada por uma medida de capital humano. Isso é função do estoque de conhecimento da economia, que por sua vez é resultado da proporção de trabalhadores empregados no setor manufatureiro. Vale ressaltar que a elevação do estoque de conhecimento aumenta o trabalho efetivo não somente no setor de manufaturas, mas em todos os setores da economia.

Com base nesse modelo, os autores concluem que economias em boom de recursos naturais - seja na forma de uma elevação dos preços internacionais, seja em função de novas descobertas - terão uma taxa de crescimento menor do que economias que não estão em boom. Isso porque a renda dos recursos naturais é distribuída aos indivíduos que, ao se tornarem mais ricos, passam a demandar mais do setor não tradable, e, em consequência, há um deslocamento de trabalho - pois se supõe que a economia está em pleno emprego - do setor manufatureiro para o não tradable. O resultado é uma menor proporção de trabalhadores nas manufaturas, menor estoque de conhecimento e de capital humano. Este movimento ocorre tanto no período inicial, na fase na qual os indivíduos são jovens, quanto no segundo período, no qual as pessoas deixaram de trabalhar.

A segunda conclusão do modelo é a de que o efeito do aumento do setor de recursos naturais no nível do PIB dos outros setores vai depender da intensidade de capital dos setores. Como exemplo, o PIB dos setores, exceto o de recursos naturais, pode inicialmente se elevar se o setor não tradable for mais capital-intensivo do que o setor de manufaturas.

O primeiro teste empírico para testar a existência de uma maldição dos recursos naturais utilizou essa versão dinâmica do modelo de doença holandesa (SACHS; WARNER, 1995), pois, como se pôde verificar na seção anterior, o modelo de Corden e Neary (1982) não é um modelo de crescimento, mas, sim, uma demonstração de mudanças na alocação de recursos (PRIEWE, 2012). Porém, antes de Sachs e Warner (1995), Auty (1993) já utilizava o termo natural resource curse com status de tese, com base em um estudo das economias em desenvolvimento ricas em combustíveis e minérios. 
A partir desse modelo endógeno de doença holandesa, Sachs e Warner (1995) argumentam acerca da existência de uma maldição dos recursos naturais. Por meio de um modelo de corte temporal, os autores testam a relação entre abundância de recursos naturais e crescimento econômico. Os resultados encontrados pelos autores sinalizam para uma relação inversa entre o crescimento econômico per capita no período de 1970 e 1989 e o percentual das exportações de commodities (agricultura, minerais e agricultura) sobre o PIB para uma amostra de 97 países em desenvolvimento. Desse modo, concluem que as economias menos abundantes em recursos naturais têm uma performance econômica superior em relação aos países mais abundantes.

A explicação para essa maldição dos recursos, segundo Sachs e Warner (1999), está no impacto negativo causado pelo boom de recursos no emprego e no produto do setor industrial através do mecanismo da doença holandesa. Isso diminuiria o crescimento econômico, pois, segundo os autores, os retornos crescentes de escala estariam restritos ao setor industrial.

\section{Críticas à Versão Dinâmica e Estática da Doença Holandesa}

O trabalho de Sachs e Warner (1995) foi alvo de diversas críticas, em termos teóricos e metodológicos. No que diz respeito à utilização de um modelo baseado na teoria do crescimento endógeno, diversos problemas podem ser apontados, além, é claro, das inúmeras simplificações adotadas, as quais são muito distantes da realidade. Primeiramente, na teoria de crescimento endógeno, a substituição de fatores entre os diferentes setores pode ser dificultada se os bens de capital não forem homogêneos. Outra crítica é com relação à negligência de questões quanto à escala produtiva (pois o que importa no modelo é a proporção de trabalhadores no setor gerador de conhecimento). Por fim, considerar que o salário é determinado de forma exógena conforme o poder de barganha dos trabalhadores implica rejeitar a tese presente na teoria de crescimento endógeno de que os salários são definidos de forma endógena ${ }^{6}$ (SERRANO; CESARATTO, 2002).

Ademais, uma hipótese - a da maldição dos recursos naturais - construída a partir de uma análise do tipo cross-section corre o risco de estar viesada pelo corte temporal, pela arbitrariedade dos países selecionados, ou pode sofrer do viés da variável omitida. Além disso, em regressões do tipo cross-section utiliza-se como variável a média do crescimento para vários anos, além de não se considerar o efeito da variação dos preços das commodities, o que pode conduzir a resultados equivocados.

6 Para mais críticas aos modelos de crescimento endógeno, ver Serrano e Cesaratto (2002). 
Collier e Goderis (2007) apresentam cinco críticas à metodologia cross-section presente em Sachs e Warner (1995): a) utiliza a média do crescimento como variável independente; b) não considera os efeitos dos preços das commodities; c) não é adequada para testar os canais ${ }^{7}$ propostos pela literatura da maldição dos recursos naturais; d) o seu modelo tem o viés da variável omitida; e) não possibilita separar os efeitos de curto prazo dos efeitos de longo prazo.

Mesmo assim, as conclusões dos autores vão ao encontro das proposições de Sachs e Warner (1995), ao tornar essa teoria mais flexível através do uso de uma hipótese ad hoc para determinar se os recursos naturais seriam uma "bênção" ou uma "maldição". Essa hipótese utiliza um restrito conceito de instituições - direitos de propriedade, governança, transparência, rent-seeking - para explicar porque a maldição dos recursos não teria acometido determinadas nações ricas em recursos (COLLIER; GODERIS, 2007). ${ }^{8}$

Por sua vez, Lederman e Maloney $(2007,2008,2012)$ estão entre os principais críticos do trabalho de Sachs e Warner (1995). Seu principal ponto de argumentação é em relação à proxy para abundância de recursos naturais - exportações de recursos naturais sobre o PIB. A utilização das exportações brutas, e não líquidas, como proxy ofusca o caso de países que são meros reexportadores de recursos naturais. Outra sugestão dos autores, baseados em Leamer (1987), é ponderar as exportações líquidas de recursos naturais pela quantidade de trabalhadores. Ao replicar os testes em cross-section de Sachs e Warner (1995) com as exportações líquidas de commodities por trabalhador, Lederman e Maloney (2007, 2008) encontram uma relação positiva entre abundância de recursos naturais e crescimento econômico.

Nesse sentido, cabe ressaltar que a América Latina, em termos per capita, não é tão rica em recursos naturais como se supõe comparativamente aos países desenvolvidos ricos em recursos naturais, como Austrália, Canadá, Nova Zelândia e Noruega, que permanecem ricos em recursos naturais mesmo quando ponderados pelo tamanho da população9 (SINNOTT; NASH; TORRE, 2010).

7 Lederman e Maloney (2008) apresentam as diferentes explicações para a maldição dos recursos naturais: a) tendência ao declínio dos preços reais de commodities; b) menor acúmulo de capital físico e humano e produtividade e externalidades inferiores; c) doença holandesa; d) enfraquecimento das instituições devido aos recursos naturais. Sachs e Warner separam a literatura para a relação inversa entre crescimento econômico e abundância de recursos naturais em: a) argumentos de caráter político e econômico; b) comportamento rent-seeking, que ocorre na disputa pelas rendas originadas da exploração dos recursos naturais; c) doença holandesa; d) hipótese de Prebisch e Singer; e) reduzido potencial de encadeamentos para frente e para trás no setor de recursos naturais comparado com o setor manufatureiro; f) diminuição do processo de learn-by-doing.

8 As conclusões desse trabalho poderiam ser facilmente aceitas, não fossem as no mínimo duvidosas proxies, como salientou Priewe (2012), para "boa governança", como a fração da população que fala línguas europeias ou a distância da linha do Equador.

9 Ver a Figura 2.2 de Sinnott, Nash e Torre (2010, p. 6). 
Para Lederman e Maloney (2007, 2008), há ainda problemas de endogeneidade com a proxy de Sachs e Warner (1995), pois não necessariamente a pobreza dos países seria explicada pela sua estrutura exportadora; a causalidade pode ser inversa: devido ao fato de esses países serem pobres, não restaria alternativa que não fosse exportar os seus recursos naturais. Em outras palavras, para Sachs e Warner (1995), a explicação da pobreza está na exportação de recursos naturais, enquanto, para Lederman e Maloney $(2007,2008)$, a pobreza explica a exportação de recursos naturais.

Sinnott, Nash e Torre (2010) sugerem medidas alternativas para a abundância de recursos naturais como forma de evitar problemas de endogeneidade ao sugerir o estoque de capital natural per capita calculado pelo Banco Mundial. Ao utilizar essa variável, os autores encontram uma relação positiva com o crescimento econômico.

Diversos trabalhos utilizam variáveis para captar a exogeneidade dos recursos naturais - como, por exemplo, o estoque de reservas minerais por trabalhador ou per capita - e também encontram ou uma relação positiva entre recursos naturais e crescimento econômico, ou nenhuma associação entre abundância de recursos e lento crescimento econômico (DAVIS, 1995; WRIGHT; CZELUSTA, 2004; ALEXEEV; CONRAD, 2009).

Stijns (2005) critica a forma como Sachs e Warner (1995) apresentam o problema da maldição dos recursos naturais, pois sugerem implicitamente que é melhor não ter recursos naturais do que tê-los, ou que é melhor não explorar os recursos que estão à disposição, o que é contra intuitivo e uma proposição difícil de sustentar.

O autor não contesta a ideia de Sachs e Warner (1995), que uma elevada intensidade de exportações de recursos naturais pode ser associada a um padrão de crescimento mais lento; tampouco tenta afirmar que a posse de recursos naturais conduzirá a economia a taxas mais elevadas de crescimento econômico naturalmente. O que o autor discorda é com relação à proposição de que a produção de recursos naturais ocorre em detrimento da produção manufatureira, com a consequente diminuição do processo de learn-by-doing e do crescimento econômico.

Já Manzano e Rigobón (2007) sugerem que a explicação para a correlação inversa entre recursos naturais e crescimento econômico de Sachs e Warner (1995) não estaria na abundância de recursos naturais, mas, sim, na dependência financeira e na vulnerabilidade externa dos países contidos na amostra, nos anos 1970 e 1980, o período analisado pelos autores.

Em outras palavras, os recursos naturais por si só não explicariam a sua correlação inversa com o crescimento econômico, mas, sim, o fato de os países em desenvolvimento ricos em recursos naturais durante o boom de preços de commodities nos anos 70 do século passado terem se endividado excessivamente, o 
que os levou à situação de insolvência na década de 80, quando os preços internacionais de commodities desabaram e as condições de liquidez internacional restringiram-se.

Ciccantell e Smith (2005, p. 13, tradução nossa) também criticam com veemência a tese da maldição dos recursos naturais:

Essa ridícula alegação de causalidade com base na correlação entre a riqueza dos recursos naturais e a pobreza em ex-colônias é reconfortante para os estados centrais e empresas mineiras que se beneficiam do pagamento de baixos preços das matérias--primas, mas o absurdo de culpar as vítimas do imperialismo e do neocolonialismo em distribuir mal as rendas inesperadas a partir do petróleo e outras indústrias minerais é, na melhor das hipóteses, a-histórica e apologética, em vez de analítica.

Segundo Lederman e Maloney (2007), a maldição dos recursos naturais seria um mito, o que não significa a ausência de desafios para as economias abundantes. O principal deles é a forma como esses recursos serão utilizados. Os autores consideram fundamental a destinação dos recursos para diversificar a economia, sem esquecer, conforme Venables (2007), que as vantagens competitivas não estão dadas, que são endógenas e podem ser desenvolvidas através de políticas destinadas para esse fim. Ademais, para Lederman e Maloney (2007, p. 24, tradução nossa),

A abundância de recursos naturais não é, necessariamente, o único determinante da estrutura de produção e diversificação nos países em desenvolvimento. Na verdade, o acúmulo de conhecimento, o nível de infraestrutura e a qualidade da governança parecem determinar não só o que os países produzem e exportam, mas também a forma como as empresas e os trabalhadores produzem qualquer tipo particular de bem.

Portanto, de toda a análise feita até aqui, e de acordo com Silva (2008), pode-se afirmar que a abundância de recursos naturais não significa uma "maldição" intransponível, visto a existência de casos de sucesso entre os países ricos em recursos naturais, mas também não torna menos importante para os países "abençoados" os esforços para a diversificação produtiva e exportadora na direção dos setores com maior conteúdo tecnológico.

Concernente à versão estática do modelo de doença holandesa, Priewe (2012) lista uma série de críticas ao core model de Corden e Neary (1982) e aos 
modelos de doença holandesa que utilizam seus princípios. A primeira delas é o fato de o modelo estar centrado muito mais em questões alocativas (estáticas) do que propriamente no crescimento econômico (dinâmicas). Em segundo lugar, os pressupostos são restritivos e muito simplificados. Um terceiro ponto é quanto à possibilidade da elasticidade da oferta de trabalho em relação à demanda não ser perfeita. Uma quarta sugestão é quanto à possibilidade de incorporar o governo no modelo, pois assim haveria a possibilidade de estabilizar a economia, administrar as rendas, mitigar a valorização real da moeda e oferecer subsídios à indústria.

Entretanto, a principal crítica é quanto ao modelo ter caracterizado uma economia de trocas diretas - escambo -, na qual os salários são calculados em quantidades de produtos. Ao transformar esse modelo em uma economia monetária da produção, há possibilidade de "cura da doença" através de política monetária e, especialmente, de política cambial (PRIEWE, 2012).

As evidências coletadas por Davis (1995) também entram em desacordo com as proposições da doença holandesa. Em muitas economias minerais, a desindustrialização não ocorreu, conforme Auty e Evans (1994), e, em alguns casos, o setor industrial cresceu, de acordo com Fardmanesh (1991).

Priewe (2012) afirma que atualmente é o diferencial de taxa de juros entre os países o principal motivo para a entrada dos fluxos de capitais e, consequentemente, para as flutuações na taxa de câmbio, e não os fluxos de comércio, o que vai de encontro com os mecanismos de doença holandesa (PRIEWE, 2012).

Além dessa crítica, Medeiros (2013, p. 151) aponta mais duas inconsistências nas explicações para a doença holandesa. Primeiramente, não há provas da substituição de produtos industriais por recursos naturais, pelo contrário, em momentos de boom das commodities a produção industrial em geral tende a se expandir em meio ao relaxamento da restrição externa. Em segundo lugar, a taxa de câmbio não é o determinante exclusivo para a especialização produtiva e exportadora e para a alocação de fatores entre os setores tradables e não tradables. Por esse motivo, o autor considera a "heterogeneidade externa" (MEDEIROS, 2011) um conceito mais apropriado para a situação de "[...] desequilíbrio estrutural entre a produtividade do setor exportador e o resto da economia [...]” (MEDEIROS, 2013, p. 152).

Nesse mesmo sentido, Fishlow e Bacha (2010) relembram que a diversificação da estrutura produtiva não necessariamente será refletida no padrão comercial, ou seja, diversificação produtiva e diversificação exportadora são conceitos diferentes, os quais não necessariamente são simultâneos.

Explicando melhor, um país diversificado, mas com substanciais dotações de recursos naturais, pode continuar com elevada participação das exportações de recursos naturais, mesmo que internamente esteja ocorrendo um processo de desenvolvimento em direção aos setores secundário e terciário. Noruega, Austrá- 
lia, Canadá, Finlândia, Nova Zelândia, Suíça e Estados Unidos provaram que é possível a diversificação produtiva a partir dos recursos naturais.

\section{Considerações Finais}

Este artigo teve como objetivo principal discutir a ideia de doença holandesa, por meio da apresentação do pensamento que o precedeu, assim como através da exposição dos modelos estático e dinâmico (maldição dos recursos naturais). Discutiram-se as principais críticas e limitações destes modelos, com destaque para as suas hipóteses simplistas.

Relacionado ao modelo dinâmico, aplicam-se as mesmas críticas dos modelos de crescimento endógeno em geral. Destacam-se também os inúmeros problemas, principalmente os metodológicos da afirmação de que economias ricas em recursos naturais serão acometidas por uma maldição perpétua e determinista explicada pelo mecanismo da doença holandesa.

Quanto ao modelo estático, e mesmo em relação à versão estruturalista da doença holandesa, quando utilizados como explicação para perda de participação do produto e emprego da indústria há pelo menos dois fatores adicionais que vão de encontro a essa suposição: a) atualmente os movimentos de apreciação cambial ocorrem principalmente em função de saldos positivos na conta capital e financeira; e b) um aumento do déficit comercial pode ser função de uma produção antes destinada ao mercado externo ter se voltado a um mercado interno mais rico. Ou seja, há uma diferenciação conceitual entre especialização exportadora e produtiva.

No que tange às orientações no campo normativo, é papel do Estado o estímulo ao setor industrial, por exemplo, através de política fiscal, macroeconômica e de estímulo ao desenvolvimento tecnológico. No tocante aos países com abundância de recursos naturais, cabe ao Estado o desenvolvimento com foco nos encadeamentos para frente e para trás no setor de recursos naturais e exploração das interdependências entre a indústria e o setor primário.

Porém, não é demais ressaltar, especialmente para os países periféricos, que as orientações políticas no âmbito doméstico são condicionadas pelas relações políticas internas e externas. Portanto, a adoção, ou não, de determinada política depende do grau de autonomia do país em questão. A pertinência desta visa evitar o nacionalismo metodológico, muitas vezes presente no debate sobre desenvolvimento econômico.

Por fim, cabe ressaltar que esta avaliação crítica não tem o objetivo de minimizar as preocupações quanto à desindustrialização, tampouco negar a evidência empírica de que os países com maior especialização produtiva tendem a ter um crescimento econômico menos robusto. O que este estudo procurou fazer foi mi- 
nimizar a culpa que recai sobre os recursos naturais de todos os problemas que o setor industrial enfrenta. Dessa forma, a relação indústria-recursos naturais não necessariamente é de oposição, e não se possui base suficiente para se afirmar que há uma diminuição automática do setor industrial frente a um boom nos recursos naturais. É nesse sentido que a discussão teórica e metodológica presente neste artigo visa contribuir para o debate.

\section{Referências}

ALEXEEV, M.; CONRAD, R. The elusive curse of oil. Review of Economics and Statistics, Cambridge, v. 91, n. 3, p. 586-598, Aug. 2009. Disponível em: <http://www.mitpressjournals. org/doi/abs/10.1162/rest.91.3.586?journalCode=rest\#.VPihxnc-BGM >. Acesso em: 31 jan. 2015 .

AUTY, R. M. Sustaining development in mineral economies: the resource curse thesis. New York: Taylor and Francis, 1993.

AUTY, R. M.; EVANS, D. V. Trade and industrial policy for sustainable resource-based development: policy issues, achievements and prospects. Geneva: UNCTAD, 8 mar. 1994. Disponível em: < http://unctad.org/en/docs/pocomd33.en.pdf>. Acesso em: 25 fev. 2015.

BOIANOVSKY, M. Commodities, recursos naturais e crescimento: um estudo através da história do pensamento econômico. In: OREIRO, J. L.; PAULA, L. F.; BASILIO, F. (Org.). Macroeconomia do desenvolvimento: ensaios sobre restrição externa, financiamento e política macroeconômica. Recife: Editora Universitária UFPE, 2012.

BRESSER-PEREIRA, L. C. A tendência à sobre apreciação da taxa de câmbio. Econômica, Rio de Janeiro, v. 11, n. 1, p. 7-30, jun. 2009. Disponível em: < http://www.bresserpereira. org.br/papers/2009/A_tendencia_sobreapreciacao_taxa_cambio.pdf $>$. Acesso em: 01 jan. 2015.

CICCANTELL, P.; SMITH, D. A. Nature, raw materials, and political economy: an introduction. In: CICCANTELL, P.; SMITH, D. A.; SEIDMAN, G. Nature, raw materials, and political economy. London: Elsevier, 2005

COLLIER, P.; GODERIS, B. Commodity prices, growth, and the natural re-source curse: reconciling a conundrum. Oxford, UK: Centre for the Study of African Economies, Aug. 2007. p. 1-41. (Working Papers Series, n. 15). Disponível em: <http://www.csae.ox.ac.uk/ workingpapers/pdfs/2007-15text.pdf>. Acesso em: 23 jan. 2015.

CORDEN, W. M. Booming sector and dutch disease economics: survey and consolidation. Oxford Economic Papers, Oxford, v. 36, n. 3, p. 359-80, Nov. 1984. Disponível em: < http:// www.jstor.org/discover/10.2307/2662669?sid $=21105543858971$ Euid $=70$ E uid $=2$ Euid $=212$ 9E्Guid=4Euid=3737664> . Acesso em: 28 jan. 2015.

CORDEN, W. M.; NEARY, J. P. Booming sector and de-industrialisation in a small open economy. Economic Journal, Cambridge, v. 92, n. 368, p. 825-848, Dec. 1982. Disponível em: <http:/www.jstor.org/discover/10.2307/2232670?sid=21105543858971E Euid =4EUuid= $70 \mathcal{E}$ uid $=3737664 \mathcal{E}$ uid $=2129$ E uid $=2>$. Acesso em: 23 jan. 2015 . 
DAVIS, G. A. Learning to love the dutch disease: evidence from the mineral economies. World Development, Oxford, v. 23, n. 10, p. 1765-1779, Oct. 1995. Disponível em: <http:// www.sciencedirect.com/science/article/pii/0305750X9500071J >. Acesso em: 22 jan. 2015.

FARDMANESH, M. Dutch disease economics and the oil syndrome: an empirical study. World Development, Oxford, v. 19, n. 6, p. 711-717, 1991. Disponível em: <http://www. sciencedirect.com/science/article/pii/0305750X9190205V>. Acesso em: 25 fev. 2015.

FISHLOW, A.; BACHA, E. Recent commodity price boom and Latin American Growth: more than new bottles for an old wine? In: OCAMPO, J. A.; ROS, J. (Ed.). Handbook of Latin American Economics. Oxford: Oxford University Press, 2010.

LEAMER, E. E. Paths of development in the three-factor, n-good general equilibrium model, The Journal of Political Economy, Chicago, v. 95, n. 5, p. 961-999, Oct.1987. Disponível: <http://links.jstor.org/sici?sici=0022-3808\%28198710\%2995\%3A5\%3C961\%3APODITT\%3E 2.0.CO\%3B2-0>. Acesso em: 31 jan. 2015.

LEDERMAN, D.; MALONEY, W. F. Does what you export matter? Search of empirical guidance for industrial policies. Washington, D.C.: The World Bank, 2012. Disponível em: $<$ https://www.imf.org/external/np/seminars/eng/2013/spr/pdf/malo2.pdf>. Acesso em: 16 out. 2014.

LEDERMAN, D.; MALONEY, W. F. In search of the missing resource curse. Economía, v. 9, n. 1, p. 1-56, Fall 2008. Disponível em: <http://muse.jhu.edu/journals/eco/summary/ v009/9.1.lederman.html>. Acesso em: 16 out. 2014.

. Trade structure and growth. In: . Natural resources: neither curse nor destiny. Washington, D.C.: Standford University Press, 2007. Disponível em: < http://siteresources. worldbank.org/inttraderesearch/Resources/D.Lederman_W.Maloney_Natural_Resources_ book.pdf>. Acesso em: 16 out. 2014.

MADHAVY, H. The patterns and problems of economic development in Rentier States: the case of Iran. In: COOK, M. A. (Ed.). Studies in Economic History of the Middle East. London: Oxford University Press, 1970.

MANZANO, O.; RIGOBÓN, R. Resource curse or debt overhang? In: LEDERMAN, D.; MALONEY, W. F. Natural resources, neither curse nor destiny. Washington, D.C.: Stanford University Press, 2007. Disponível em: < http://siteresources.worldbank.org/inttraderesearch/ Resources/D.Lederman_W.Maloney_Natural_Resources_book.pdf $>$. Acesso em: 16 out. 2014.

MEDEIROS, C. A. Recursos naturais, nacionalismo e estratégias de desenvolvimento. Revista Oikos, Rio de Janeiro, v. 12, n. 2, p. 143-167, 2013. Disponível em: < http://www.revistaoikos. org/seer/index.php/oikos/article/download/344/193 >. Acesso em: 22 dez. 2014.

The political economy of the rise and decline of developmental states. Panoeconomicus, Novi Sad, v. 1, p. 43-56, Feb. 2011. Disponível em: < http://www.doiserbia. nb.rs/ft.aspx?id=1452-595X1101043M > . Acesso em: 28 fev. 2015.

MILL, J. S. Princípios de economia política: com algumas de suas aplicações à filosofia social. São Paulo: Nova Cultural, 1996. 
PRIEWE, J. Dutch disease, resource curse and development. In: UNITED NATIONS CONFERENCE ON TRADE AND DEVELOPMENT. Contemporary issues in international macroeconomics, trade and finance. New York; Geneva: United Nations, 2012. (Module 2).

SACHS, J. D.; WARNER, A. M. Natural resource abundance and economic growth. Cambridge, MA: National Bureau of Economic Research, Dec. 1995. (NBER Working Paper, n. 5398). Disponível em: <http://www.nber.org/papers/w5398>. Acesso em: 13 out. 2014.

The big push, natural resource booms and growth. Journal of Development Economics, Amsterdan, v. 59, n. 1, p. 43-76, Jun. 1999. Disponível em: < http://earth. columbia.edu/sitefiles/file/about/director/pubs/JnlofDevtEcon1999.pdf > . Acesso em: 23 set. 2014.

SEERS, D. The mechanism of an open petroleum economy. Social and Economic Studies, Washington, D.C., v. 13, n. 12, p. 233-242, June 1964. Disponível em: < http://www.jstor. org/discover $/ 10.2307 / 27853782$ ? sid $=21105560149711$ Euid $=70$ Euid $=5909624$ Euid $=2$ Eui $\mathrm{d}=3$ E Uid $=37617$ Euid $=3737664$ E uid $=37618 \mathcal{E}$ uid $=62 \mathcal{E}$ uid $=2129$ Euid $=67>$. Acesso em: 15 fev. 2015.

SERRANO, F. L. P.; CESARATTO, S. As leis de rendimento nas teorias neoclássicas do crescimento: uma crítica sraffiana. Ensaios FEE, Porto Alegre, v. 23, n. 2, p. 699-730, 2002.

SILVA, A. C. M. Estrutura produtiva e especialização comercial: observações sobre a Ásia em desenvolvimento e a América Latina. Cadernos do Desenvolvimento, Rio de Janeiro, v. 3, n. 5, p. 81- 125, dez. 2008. Disponível em: < http://www.centrocelsofurtado.org.br/arquivos/ image/201108311533390.CD5_0_082.pdf>. Acesso em: 02 fev. 2015.

SINNOTT, E.; NASH, J.; TORRE, A. Natural resources in Latin America and the Caribbean: beyond booms and busts? Washington, D.C.: World Bank, 2010. Disponível em: <http:// siteresources.worldbank.org/INTLAC/Resources/257803-1284336216058/FlagshipReport. pdf > . Acesso em: 13 jun. 2014.

STIJNS, J. P. C. Natural resource abundance and economic growth revisited. Resources Policy, Guildford, v. 30, n. 2, p. 107-130, 2005. Disponível em: < http://citeseerx.ist.psu.edu/ viewdoc/download?doi=10.1.1.321.8113E $\mathrm{rep}=$ rep1Etype $=$ pdf $>$. Acesso em: 31 jan. 2015.

VENABLES, A. Trade, location and development: an overview of theory. In: LEDERMAN, D.; MALONEY, W. F. Natural resources: neither curse nor destiny. Washington, D.C.: Standford University Press, 2007. Disponível em: < http://siteresources.worldbank.org/ INTTRADERESEARCH/Resources/D.Lederman_W.Maloney_Natural_Resources_book. pdf > . Acesso em: 16 out. 2014.

WRIGHT, G.; CZELUSTA, J. Why economies slow: the myth of the resource curse. Challenge, White Plans, v. 47, n. 2, p. 6-38, Mar.-Apr. 2004. Disponível em: <http://web.stanford. edu/ write/papers/Wright\%20Res\%20Curse.pdf> . Acesso em: 31 jan. 2015.

Recebido em: 26/12/2016. Aceito em: 17/03/2017. 